\title{
Investigation of meningitis outbreak after the introduction of Pneumococcal and MenA conjugate vaccines in two districts of Northern Region, Ghana from October 2015 to March 2016
}

Bumawura EE Mahamah ${ }^{1 *}$, Josephat Nyuzaghl ${ }^{1}$, Mutala Mahama ${ }^{1}$, Yakubu Eliasu ${ }^{1}$, Seidu Mudda ${ }^{1}$, Mukaila M Zankawah ${ }^{2}$ and Mohammed A Soghaier ${ }^{3}$

${ }^{1}$ Ghana Health Service, District Health Directorate, Bole, Ethiopia

${ }^{2}$ Ghana Health Service, Metropolitan Health Directorate, Tamale, Ghana

${ }^{3}$ Directorate of Epidemiology \& Zoonotic Diseases, Sudan Federal Ministry of Health, Khartoum, Sudan

\begin{abstract}
Introduction: Despite the introduction of the Pneumococcal and Meningococcal conjugate vaccines (MenAfriVac) into the routine immunization programme in the Northern part of Ghana, Bole and Sawla-Tuna-Kalba (STK) districts experienced an outbreak of meningitis between October 2015 and March 2016.

Cerebrospinal meningitis (CSM) is a major cause of morbidity and mortality. Globally meningitis mortality ranges between $2 \%$ and $30 \%$, and $36 \%$ to $50 \%$ in Ghana. The northern part of Ghana lies within the African "meningitis belt" that extend from Senegal to Ethiopia making it prone to repeated meningitis outbreaks.

Objective: This investigation was conducted to determine the cause of the outbreak in the two districts after the introduction of Pneumococcal and MenA Conjugate Vaccines.

Methods: Field investigation conducted to determine the cause and appropriate control measures instituted to control meningitis outbreak in Bole and STK districts. Cases were detected using a standard surveillance case definition for meningitis. Case based forms were used to collect data on demographic and clinical characteristics of cases. Laboratory results were obtained from samples of specimen from suspected cases sent to the laboratory for standard microbiological investigation. Active case findings were conducted in the communities where cases were reported. Consulting room and in-patient registers in the district hospital and all health centres including community register were reviewed during the period.

Results: Of the 39 confirmed cases, the highest percentage of cases were caused by Streptococcus pneumonia (54\%) and Neisseria meningitides (38\%) specifically serogroup W135. In two (2) cases more than one organism was found. Majority (61\%) of the cases were males, also, $76 \%$ of the cases were less than 30 years. Seventy five percent $(75 \%)$ of the cases were in the Bole district. Overall case fatality rate (CFR) for the two districts was $33 \%$. Analysis by sex showed a higher fatality rate among males (37\%) than females (23\%).

Conclusion: This investigation found that the outbreak was predominantly caused by two strains of meningitis causing organisms. Intensive surveillance, health education, sensitization of clinicians and proper case management helped to contain the outbreak. Logistic supplies especially specific laboratory reagents such as PCR needs urgent attention to help in timely characterization of disease-causing organisms and guiding the plan for vaccination activities using the isolated serogroup. Apart from mass vaccination campaigns targeting different causative agents, high PCV and Hib coverage in routine EPI should be maintained. The introduction of Pneumococcal and MenA conjugate vaccines was irrelevant in this outbreak since it was caused by different organisms.
\end{abstract}

\begin{abstract}
Abbreviations: CBSVs: Community-Based Surveillance Volunteers; CFR: Case Fatality Rate; CHAG: Christian Health Association of Ghana; CHPS: Community-Based Health Planning and Services; CSF: Cerebrospinal Fluid; CSM: Cerebrospinal Meningitis; DISC: District Internal Security Committee; GHS: Ghana Health Service; HC: Health Center; HibB: Haemophilus Influenza type B; HQ: Head Quarters; LP: Lumber Puncture; MenA: Neisseria Meningitides Serotype A; PCR: Polymerase Chain Reaction; RHD: Regional Health Directorate; SD: Sub-District; SP: Streptococcal Pneumonia; +ve: positive; -ve: Negative

\section{Introduction}

Cerebrospinal meningitis (CSM) is a major cause of morbidity and mortality in many parts of the world [1-3]. Globally meningitis mortality ranges between $2 \%$ and $30 \%$ [4-6], and that of Ghana is estimated to range from $36 \%$ to $50 \%[2,6]$. Several different bacteria can cause meningitis. Beyond the neonatal period, over $90 \%$ of infections are caused by Streptococcus pneumoniae (S. pneumoniae), Haemophilus influenza (H. influenza) and Neisseria meningitidis (N. meningitides) [7].

${ }^{\star}$ Correspondence to: Bumawura Ewuntomah E Mahamah, Ghana Health Service, District Health Directorate, Bole, Ethiopia, Tel: +233 200545855/233244432656, E-mail: mzankawah@yahoo.co.uk

Key words: meningitis, outbreak, investigation, Bole

Received: December 12, 2019; Accepted: January 16, 2020; Published: January 20,2020 
Mahamah BEE (2020) Investigation of meningitis outbreak after the introduction of Pneumococcal and MenA conjugate vaccines in two districts of Northern Region, Ghana from October 2015 to March 2016

Meningitis is a preventable disease largely through the use of vaccines. Haemophilus influenzae type $B$ (Hib) used to be a common cause of bacterial meningitis in children less than 4 years worldwide before the Hib vaccines [8] was developed and introduced into Expanded Programs of immunization (EPI) in 1987. However, bacterial meningitis still occurs in epidemic proportions and Neisseria meningitides is known to cause most epidemics. Though these outbreaks can occur in any part of the world, the largest outbreaks have been observed in the sub-Saharan African countries which lie along what is mostly described as the meningitis belt. African meningitis belt extends from Ethiopia in the East to Senegal in the West, as described by Lapeysonnie [9-10]. Meningococcal meningitis has been known to be the only form of bacterial meningitis that causes epidemics. However, in many African countries including Ghana which lies within the meningitis belt, epidemic of acute bacterial meningitis caused by different subtypes of $N$. meningitides and S. pneumoniae have been reported [9,11-16].

Large populations are affected by annual outbreaks of Meningococcal meningitis during the dry season. Devastating epidemics with peak incidence approaching 1,000 cases per 100,000 population [17] occur every 8-12 years. Most of these epidemics have been attributed to Neisseria meningitides serogroup A (MenA).

MenA mass vaccination was carried out in Ghana among people aged 1-29 years including pregnant women and lactating mothers in three regions of northern Ghana (Northern, Upper East and Upper West) from $9^{\text {th }}-18^{\text {th }}$ October 2012 with the expectation that it will help prevent the incidence of meningitis in the northern part of Ghana; Bole district recorded more than $95 \%$ vaccination coverage of the target group for the campaign. Following the mass vaccination campaigns, case base surveillance system has been implemented in the country. Subsequently, Pneumococcal Conjugate Vaccine (PCV) was also introduced into routine EPI in 2012 and MenA vaccine was also scheduled to be introduced into routine EPI by December 2016 . Case base surveillance is useful to effectively monitor the disease trend and determine cases attributed to other meningitis causing organisms, it also provides substantial information regarding mass vaccination campaigns and MenA vaccine effectiveness. The purpose of this investigation was therefore to determine the cause of the outbreak in the two districts after the introduction of Pneumococcal and MenA Conjugate Vaccines.

\section{Methodology}

\section{Study area}

Bole and Sawla-Tuna-Kalba (STK) districts are located in the western part of the northern region of Ghana. STK used to be part of Bole district until 2004 when it was curved out to form a district of its own. The two districts share the same traditional, cultural, geographic and climatic characteristics. The estimated populations for Bole and STK as at 2016 are 73,120 and 116,928 respectively according to the Ghana population and housing census, 2010. The two districts share borders with La Cote D'Ivoire in the west and the East with West Gonja, Central Gonja and North Gonja districts. To the south Bole district shares borders with Tain, Kintampo North and Kintampo South districts whiles STK shares borders with Wa West to the North. The discovery and increased in unregulated gold mining activities popularly referred to as "galamsey" in Ghana has attracted people all over Ghana and the Bole district, particularly in communities such as Tinga, Banda Nkwanta, Dollar power among others where these activities take place. The influx of such large numbers of people influenced the socio-demographic dynamics in the district with increased risk of transmission of communicable diseases.

\section{Study design}

A descriptive field investigation study was employed to determine of meningitis outbreak in Bole and STK districts of northern region of Ghana.

\section{Study population}

All clinically suspected meningitis cases reported throughout the outbreak period to health facilities were included in this analysis. Cases with incomplete clinical records or missing data were excluded.

\section{Study period}

The investigation period was from October 2015 to March 2016.

\section{Data collection tools and analysis}

Cases were detected using standard surveillance case definitions for meningitis. Case based forms were used to collect data on demographic and clinical characteristics of cases. Laboratory results were obtained from specimen samples of suspected cases sent to the laboratory for investigation. Active case findings were conducted in the communities where cases were reported. Consulting room and in-patient registers in the district hospital and all health centres including community registers were reviewed during the period.

All data collected were entered into a Microsoft excel template. Descriptive statistics were analysed in the form of frequency distribution tables for all variables including sex and geographical distribution. Median age and age range were determined. Epidemiological curves showing time trends (date of onset and week of reporting) as well as date cases reported to the health facilities were generated.

\section{Background context}

On the $19^{\text {th }}$ October 2015, a 9-year-old boy from Mankuma was admitted to the Bole district hospital with headache, fever, and neck stiffness/pain. Lumbar Puncture (LP) could not be done since the patient died shortly later (Tuesday $20^{\text {th }}$ October 2015). Subsequently, between November and December 2015, three other cases with similar signs and symptoms tested positive for streptococcus pneumonia; one of the cases was from Gindabuo in STK district while the other two were from communities within the Bole district. By week 2 of 2016 Bole district had exceeded its alert threshold of 4 cases per week when 6 additional cases were reported. The District Health Team immediately started preparing outbreak response measures and activated the District Epidemic Response Team. Subsequently, the district health authorities with approval from the Regional Health Directorate (RHD) declared the situation as an outbreak prior to reaching its epidemic threshold because two of its neighbouring districts; Wenchi and Tain in the Brong Ahafo region had already declared meningitis outbreaks respectively. The District Epidemic Management Team had technical support from both the national and northern Regional Surveillance teams to effectively control the outbreak. The response team implemented control measures including case management, contact tracing, community education on signs and symptoms and the need to report early to the nearest health facility. Community health volunteers were also used to identify, and report suspected cases to health facilities. Health official across the districts also conducted active case finding. All CSF samples collected were sent to the public health reference laboratory at Tamale Teaching Hospital the in Northern region of Ghana for PCR testing and serogrouping. 


\section{Case definition}

The team made a broad case definition as a method of including as many possible cases for CSF collection for testing and confirmation. In the field investigation, suspected case of meningitis was defined as "any person with sudden onset of fever $\left(38.0^{\circ} \mathrm{C}\right.$ axillary) and any one of the following signs: neck stiffness, altered consciousness or other meningeal sign resident in the Bole district”.

A probable case was a suspected case with CSF examination showing at least turbid appearance or leukocytosis $(>100 \mathrm{cell} / \mathrm{mm} 3)$ or leukocytosis (10-100 cell/mm3 and either an elevated protein $(>$ $100 \mathrm{mg} / \mathrm{dl})$ or decrease glucose $(<40 \mathrm{mg} / \mathrm{dl})$.

A confirmed case was defined as "any suspected meningitis case confirmed by the isolation of Neisseria meningitidis, Streptococcal pneumonia or Haemophilus influenza from the person's cerebrospinal fluid".

\section{Results}

The range of ages among cases reported was 4-78 years with a median age of 17 years. A greater percentage (76\%) of the cases were below the age of 30 years.

Majority (61\%) of the cases were males, overall, case fatality rate (CFR) for the two districts was 33\%. Analysis by sex showed a higher fatality rate among males (37\%) than females (23\%). The attack rate during the epidemic was 27 per 100,000 population with inter district variations.

Of the 51 suspected cases during the period, cerebrospinal fluid from 47 cases were tested. The highest percentage of cases were caused by streptococcus pneumonia (54\%) and Neisseria meningitides (38\%) specifically serotype W135. Haemophilus influenza type B accounted for $3 \%$ of cases. In two (2) (5\%) cases, more than one organism was found (Tables 1-3, Figures 1-4).

\section{Discussion}

Meningococcal meningitis is known to be the only form of bacterial meningitis that causes epidemics. However, in many African

countries including Ghana which lies within the meningitis belt, epidemic of acute bacterial meningitis caused by different subtypes of $N$. meningitides and S. pneumoniae have been reported [09,11-16]. Bole district reports meningitis cases each year but did not crossed its epidemic threshold since 2004 until 2016 which is consistent with the 8-12-year epidemic occurrence cycle. This outbreak was largely caused by two main organisms: S. pneumonia (54\%) and N. meningitides (W135) (38\%). Findings from this investigation showed an outbreak that was sporadic with no clustering in any particular community and this presented a challenge with regards to instituting effective control measures.

The attack rate of epidemic meningococcal disease is usually in the range of $10-1,000$ per 100,000 population. During this epidemic, the overall attack rate in the two districts was 27 per 100,000 population. The attack rate in Bole was about 5 times higher than STK. A combination of conditions (environmental, host and organism) are required for an outbreak to occur. These include special climatic conditions (dry season and dust storm), immunological susceptibility of population and low socioeconomic status among others. The widespread practice of unregulated mining activities localized within several communities in the Bole district facilitates frequent movement of people across the length and breadth of the country including neighbouring Sahelean countries in and out of the district. These factors coupled

Table 1. Age group of cases

\begin{tabular}{|c|c|c|}
\hline Age group (years) & Number of cases (n) & Percent (\%) \\
\hline$<5$ & 3 & 6 \\
\hline $5-9$ & 8 & 16 \\
\hline $10-14$ & 12 & 24 \\
\hline $15-19$ & 8 & 16 \\
\hline $20-24$ & 5 & 10 \\
\hline $25-29$ & 3 & 6 \\
\hline $30-34$ & 2 & 4 \\
\hline $35-39$ & 2 & 4 \\
\hline $40-44$ & 0 & 0 \\
\hline $45-49$ & 0 & 0 \\
\hline $50-54$ & 2 & 4 \\
\hline $55-59$ & 2 & 4 \\
\hline 60 and above & 4 & 8 \\
\hline
\end{tabular}

Meningitis cases

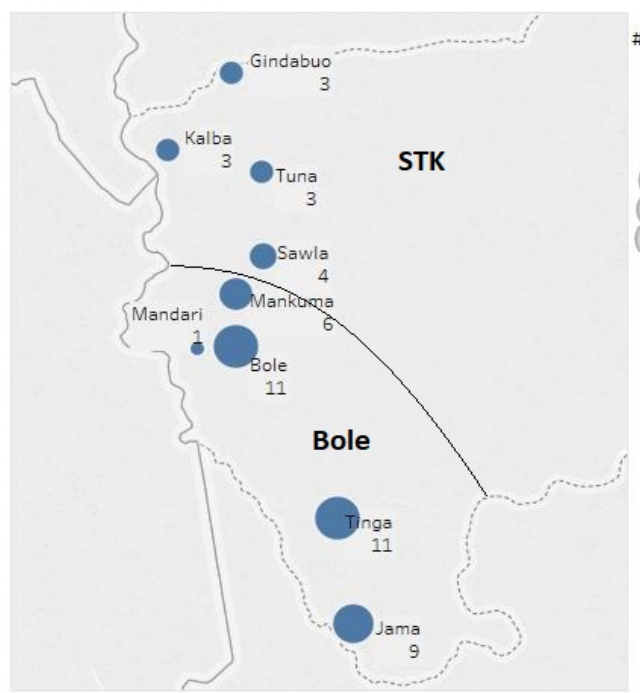

Meningitis deaths

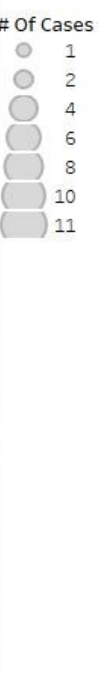

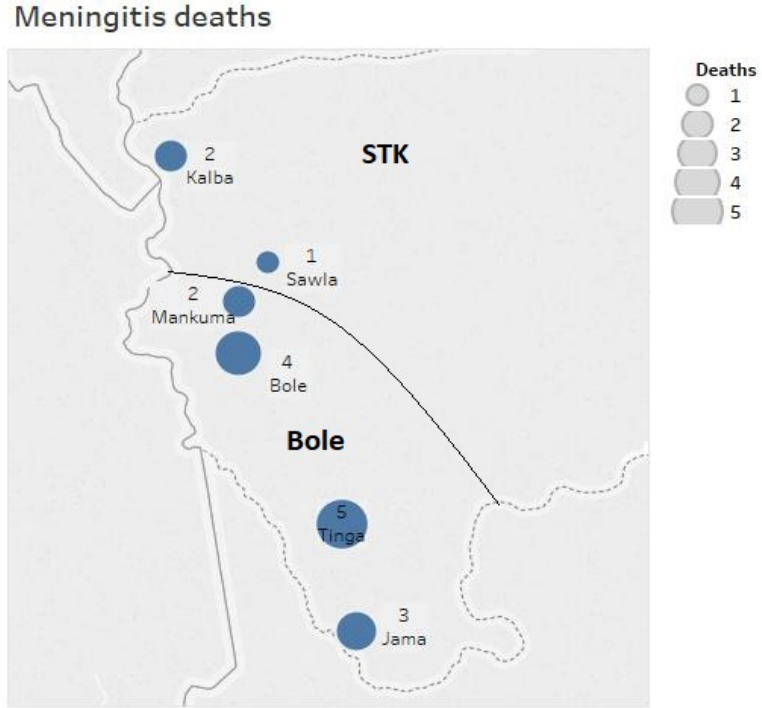

Figure 1. Spot map of meningitis cases and deaths in Bole District October, 2015-March, 2016 


\section{REPORTED MENINGITIS CASES BY WEEKS FROM WEEK 43 OF 2015 TO WEEK 12 OF 2016}

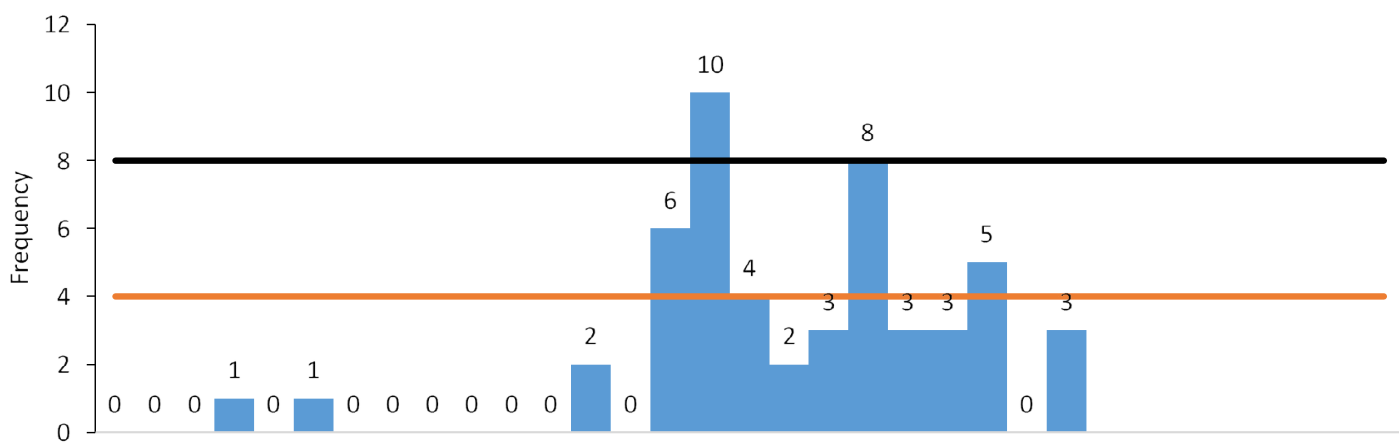

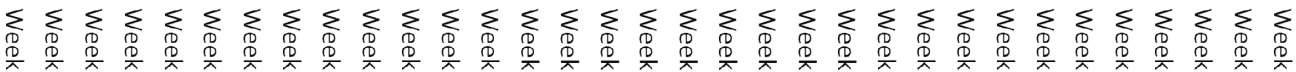

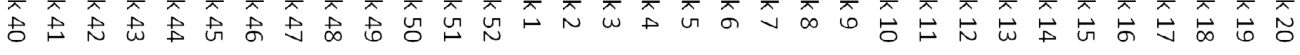
weeks

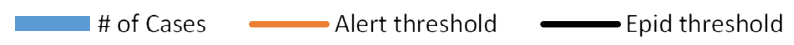

Figure 2. Epidemic curve of meningitis outbreak in Bole District as on $25^{\text {th }}$ March, 2016

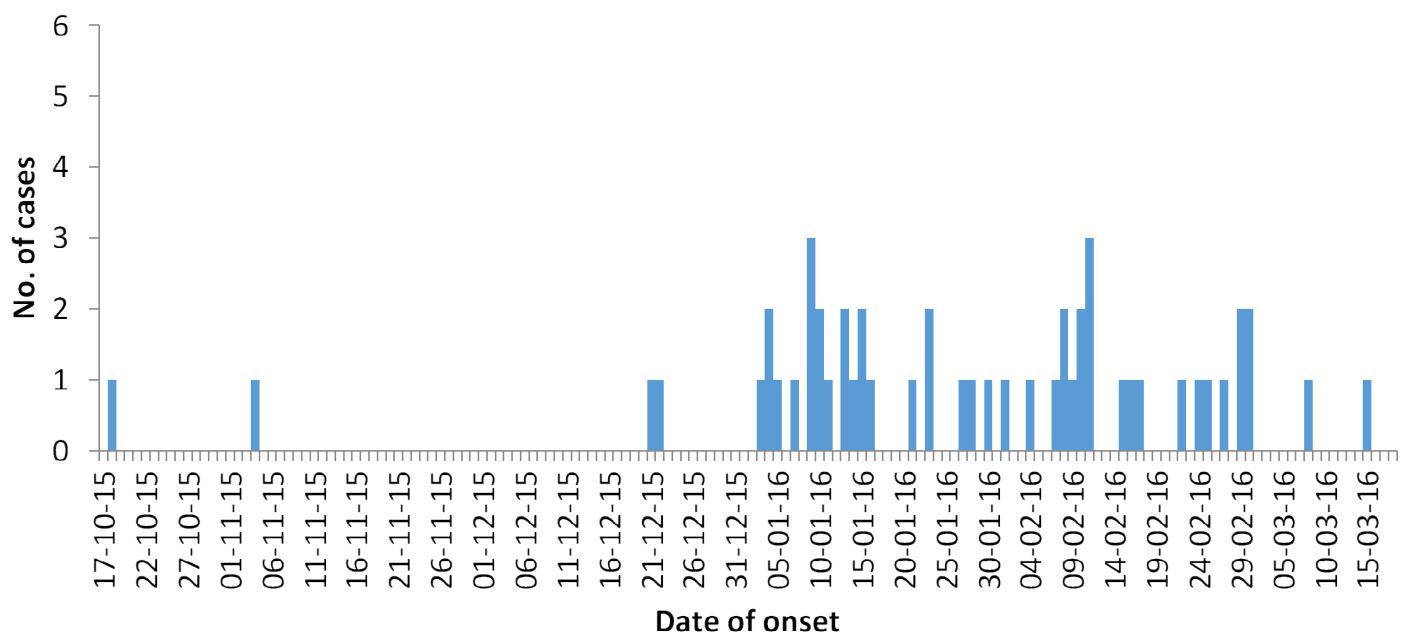

Figure 3. Suspected meningitis cases by date of onset

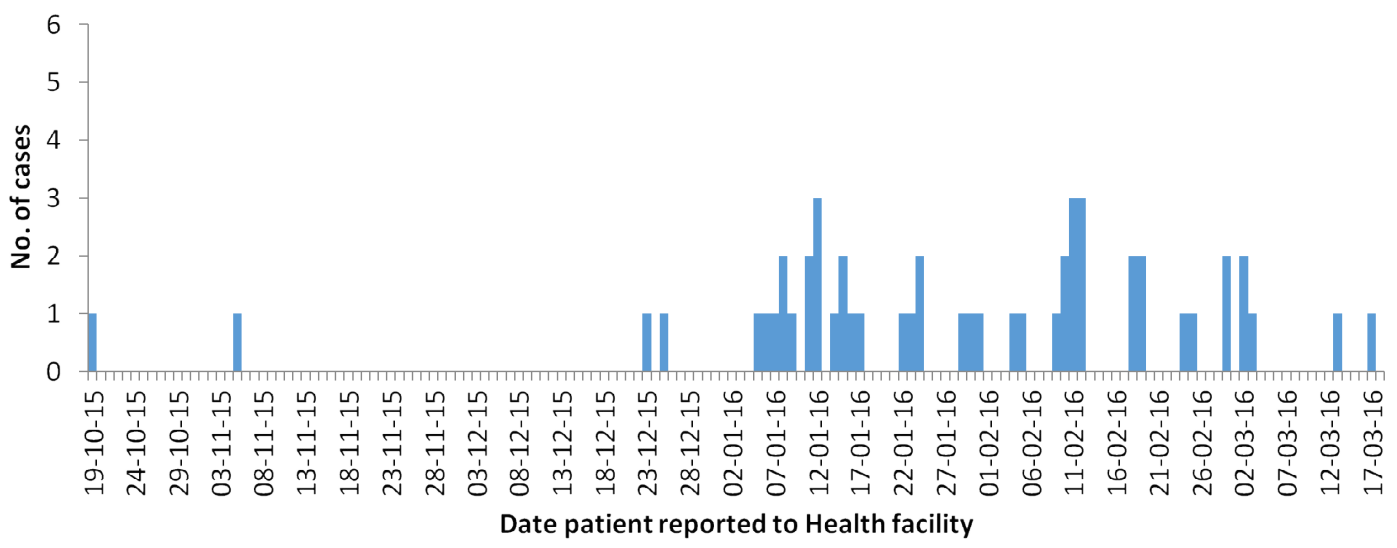

Figure 4. Date patients reported to health facility 
Mahamah BEE (2020) Investigation of meningitis outbreak after the introduction of Pneumococcal and MenA conjugate vaccines in two districts of Northern Region, Ghana from October 2015 to March 2016

Table 2. Sex distribution, attack rate and case fatality rate by districts

\begin{tabular}{|c|c|c|c|c|c|c|c|}
\hline \multirow{2}{*}{ District } & \multirow{2}{*}{ Population } & \multirow{2}{*}{ Number of cases (n) } & \multirow{2}{*}{$\begin{array}{c}\text { Attack rate/100,000 } \\
\text { population }\end{array}$} & Female & Male & \multirow{2}{*}{ Deaths } & \multirow{2}{*}{$\begin{array}{c}\text { Case fatality rate } \\
\text { (CFR) }\end{array}$} \\
\hline & & & & n (\%) & n (\%) & & \\
\hline Bole & 73120 & 38 & 52 & $13(68)$ & $25(81)$ & 14 & 37 \\
\hline STK & 116928 & 13 & 11 & $6(32)$ & $19(19)$ & 3 & 23 \\
\hline Total & 190048 & 51 & 27 & $19(37)$ & $31(61)$ & 17 & 33 \\
\hline
\end{tabular}

Table 3. Laboratory results of the outbreak investigation

\begin{tabular}{|c|c|c|c|c|c|c|c|}
\hline \multirow[b]{2}{*}{ District } & \multirow[b]{2}{*}{ No. of samples tested } & \multicolumn{2}{|c|}{ Test results } & \multicolumn{4}{|c|}{ Bacteria identified } \\
\hline & & $+\mathrm{ve}$ & -ve & Strep. Pneumonia & $\begin{array}{l}\text { N. Meningitidis } \\
\text { W135 }\end{array}$ & $\begin{array}{l}\text { Haemophilus } \\
\text { Influenzae B }\end{array}$ & $\begin{array}{c}\text { Multiple bacteria } \\
\text { identified }\end{array}$ \\
\hline Bole & 34 & 28 & 6 & $13(46)$ & $12(43)$ & $1(4)$ & $2(7)$ \\
\hline STK & 13 & 11 & 2 & $8(73)$ & $3(27)$ & 0 & 0 \\
\hline Total & 47 & $39(83)$ & $8(17)$ & $21(54)$ & $15(38)$ & $1(3)$ & $2(5)$ \\
\hline
\end{tabular}

with general environmental and specific conditions peculiar to these mining settlements including poorly ventilated housing structures and overcrowding are predisposing factors to meningitis transmission. However, there were no observed clustering of cases in these mining communities in this outbreak. The outbreak occurred within the harmattan season (a period associated with drought and dust storm) which usually occurs between December and March, a period reported to facilitate spread of meningitis. This period also occasioned performance of traditionally scheduled funerals in the districts where many people gather leading to overcrowding in poorly ventilated dwellings where the spread of virulent meningococcal is optimal [17-21].

The case fatality rates in this outbreak were consistent with other outbreaks in which S. pneumonia is reported to cause more deaths than Neisseria meningitides $[18,19]$. Case management was consistent with national guidelines $(\ldots . .$.$) but the high mortality rate was attributed$ to late reporting by patients as majority of the deaths $81.25 \%(13 / 16)$ occurred within 4 hours of presentation to the hospital. Majority of deaths $87.5 \%$ (14/16) were not active members of the national health insurance scheme (NHIS). The delay in seeking health care among those who died was largely due to financial barrier in seeking health care and also lack of adequate information in the initial phase of the outbreak according to interviews conducted with relatives of the case.

Group A meningococcus accounts for an estimated $80-85 \%$ of all cases in the meningitis belt in Ghana, with epidemics occurring at intervals of 8-12 years. The recurrent meningitis outbreaks in the northern regions of Ghana particularly, led to a mass immunization campaign conducted in the country in 2012 to address the burden of Group A meningococcus. The proportion of meningococcus serogroup A has declined dramatically following the mass vaccination.

PCV was subsequently introduced into routine EPI in the country in 2012 (three years before this current outbreak) whiles Haemophilus influenzae type b (Hib) was introduced much earlier in 2001 in Ghana targeting children below one year; these antigens are expected to protect the target population from pneumococcal and Haemophilus influenzae type $\mathrm{b}$ diseases. In this outbreak, no case due to Group A meningococcus was reported. S. pneumoniae is known to cause epidemics in children below 2 years $[18,23]$ but in this current outbreak no case was found to have occurred below 2 years (after introduction of PCV into routine vaccination). However, more than $50 \%$ of the confirmed cases were caused by $S$. pneumoniae with median age of 17 years, thus emphasizing the protective role of vaccinations either through mass vaccinations or in routine immunization (RI) activities [22]. Only one incidence was reported due to Haemophilus influenzae type b in 4 years old boy, but the immunization history of the child was not available to confirm the immunization status of the Pentavalent vaccine (PENTA). This might be due to a number of factors such as problems with immune response, not being vaccinates at all or not received the complete 3 doses of Hib.

This outbreak is not a perfect storm since other different subtypes of $N$. meningitides and S. pneumoniae are known to cause epidemics [09,11-16] of which mass vaccinations have not been conducted.

The outbreak involved more males than females in terms of attack and mortality rates; in general, morbidity and mortality rates turn to be higher in males than in females throughout life [23-25]. Females are reported to have stronger humoral and cellular immune responses to infection or antigenic stimulation than males do [25]. This increased level of immunity can be beneficial in protection against, and clearance of, a proportion of pathogens [26]. However, there has not been any known independent risk factor associated with pneumococcal meningitis disease due to $S$. pneumoniae among the age (5-15) group mostly affected in this outbreak. They may be much more susceptible to the dusty winds, cold nights and upper respiratory tract infections that combine to damage the nasopharyngeal mucosa, increasing the risk of meningococcal disease of the season [12].

In December 2015, an outbreak of Pneumococcal meningitis occurred in Tain district of which Streptococcus pneumoniae was responsible; there were also increased reports of meningitis cases due to the same organism in Wenchi, Techiman North, Nkoranza South and Atebubu districts all in the Brong Ahafo region which share long boundaries with the northern region. Other districts also reported cases of meningitides serogroup W135 namely in Techiman Municipal and Sene West in Brong Ahafo Region. Ashanti Region which lies in the forest zone reported 7 cases which is not very different from the numbers recorded in 2015. These outbreaks presents' a changing epidemiology of meningitis in Ghana along with the challenging gaps in preparedness and response of the health system to outbreaks and therefore calls for regular mass vaccinations using different antigens particularly against the popular organisms known to cause outbreaks. There is also the need to strengthen the existing surveillance systems.

\section{Conclusion}

This outbreak was caused mainly by streptococcal pneumonia confined to peoples above 3 years of age who were not targeted for PCV in routine EPI nor have been targeted for mass vaccinations. No case in the outbreak was due to Neisseria Meningitides type A, this might be an evidence of mass vaccination impact. The mortality rate was high due to late reporting of some patients. Intensive health education, durbars and appropriate case management resulted in the control of the outbreak in the Bole district. Special attention is therefore required as far as disease surveillance is concerned. The introduction 
Mahamah BEE (2020) Investigation of meningitis outbreak after the introduction of Pneumococcal and MenA conjugate vaccines in two districts of Northern Region, Ghana from October 2015 to March 2016

of Pneumococcal and MenA conjugate vaccines was irrelevant in this outbreak since it was caused by different organisms

\section{Recommendations}

Maintenance of strong cases-based disease surveillance is crucial during the coming years in the country to observe the trend and causative agents rather than Neisseria Meningitides type A. Improved supply and timely laboratory processing and feedback should be enhanced to increase effectiveness of case-based surveillance system. Special focus should be observed on peculiar cases such as beneficiaries of a particular intervention relating to a particular investigation to help in explaining events better (in this case the 4 year old case with heamaphilus influenza type B. Ensuring high performance and coverage of routing EPI in high risk districts is required to fill immunity gaps in targeted populations. Improving health education using different media such as FM radio channels will help create awareness and increase knowledge regarding prevention of the disease. Universal NHIS coverage is required to eliminate financial barrier to seeking early health care.

\section{Declaration}

\section{Ethical approval and consent to participate}

The epidemic management committee granted approval for the data of this investigation for this purpose

\section{Consent for publication}

Not applicable. No details of a particular individual's information, pictures or video is used

\section{Availability of data and materials}

The raw data used and/or analysed during the current investigation are available from the corresponding author on reasonable request

\section{Competing interest}

All the authors declared that no competing interest exist that may have played a role in the results of the outbreak investigation mission.

\section{Funding}

Not applicable, there was no funding for this investigation

\section{Authors' contributions}

BEEM was the leader of the investigation team. JN managed all the cases reported. BEEM, JN, MM, YE, and SM were the managers of the investigation and drafted the field epidemiological studies. MMZ and YE coordinated and managed the data. MM and SM supervised the field work and coordinated prevention measures advocacies. MMZ, YE and BEEM conducted the statistical analysis. MMZ and BEEM, MAS drafted the manuscript. All the authors participated intellectually in designing and preparing the study protocol. All the authors contributed and provided input to the final manuscript. All authors read and approved the final manuscript.

\section{Acknowledgement}

Authors acknowledge the following people for their immense support during the outbreak: Minister for Health; Honorable Alex Segbefia, his deputy Honorable Dr. Victor Asare Bampoe, the Director General of Ghana Health Service Dr. Ebenezer Appiah-Denkyira, Dr. F. Asiedu-Bekoe, Dr. David Opare, Kwame K. Achempem, Dr. Owen
Kaluwol, Dr. Sally-Ann Ohene (WHO team), Capt. V. Amenyedor, Northern Regional Director of Health Services; Dr. Jacob Y. Mahama, the Regional Disease Control Officer; Mr. Edward Abu Accrachie, regional surveillance officer Mr. Emmanuel J. Kando, the sub-regional head of the PHRL Mr. Abass, the Upper East Regional Director of Health Services; Dr. Kofi Issah for his kind support and guidance to the district. MDDHS of West Gonja, Techiman, Wenchi and STK and the BAR surveillance team, DCE, Mr. James Jaaga, the Bole District Assembly and DISC members, Community Based surveillance Volunteers (CBSV)and health partners (especially NEA).

\section{References}

1. Nihar Dash DP (2008) Acute Bacterial Meningitis Among Children \&1t; 5 Years of Age in Oman: A Retrospective Study During 2000-2005. J Infect Dev Ctries 2:112-115.

2. Mackie EJ, Shears P, Frimpong E, Mustafa-Kutana SN (1992) A study of bacterial meningitis in Kumasi, Ghana. Ann Trop Paediatr 12: 143-148. [Crossref]

3. Chávez-Bueno S, McCracken GH (2005) Bacterial meningitis in children. Pediatr Clin North Am 52:795-810. [Crossref]

4. van de Beek D, de Gans J, Spanjaard L, Weisfelt M, Reitsma JB, et al. (2004) Clinica features and prognostic factors in adults with bacterial meningitis. $N$ Engl $J$ Med 351:1849-1859. [Crossref]

5. Pérez AE, Dickinson FO, Rodríguez M (2010) Community acquired bacterial meningitis in Cuba: a follow up of a decade. BMC Infect Dis 10:130. [Crossref]

6. Holliman RE, Liddy H, Johnson JD, Adjei O (2007) Epidemiology of invasive pneumococcal disease in Kumasi, Ghana. Trans R Soc Trop Med Hyg 101: 405-413. [Crossref]

7. Edmond K, Clark A, Korczak VS, Sanderson C, Griffiths UK, et al. (2010) Global and regional risk of disabling sequelae from bacterial meningitis: a systematic review and meta-analysis. Lancet Infect Dis 10:317-328. [Crossref]

8. Martin M1, Casellas JM, Madhi SA, Urquhart TJ, Delport SD, et al. (2004) Impact of Haemophilus influenzae Type b Conjugate Vaccine in South Africa and Argentina. Pediatr Infect Dis J 23: 842-847. [Crossref]

9. Introduction. Bull World Health Organ. 1963;28(Suppl):3-5.

10. Molesworth AM, Thomson MC, Connor SJ, Cresswell MP, Morse AP, et al. (2002) Where is the meningitis belt? Defining an area at risk of epidemic meningitis in Africa. Trans R Soc Trop Med Hyg 96: 242-249. [Crossref]

11. Weber MW, Herman J, Jaffar S, Usen S, Oparaugo A, et al. (2002) Clinical predictors of bacterial meningitis in infants and young children in The Gambia. Trop Med Int Health 7: 722-731. [Crossref]

12. Besancenot JP, Boko M, Oke PC (1997) Weather conditions and cerebrospinal meningitis in Benin (gulf of Guinea, West Africa). Eur J Epidemiol 13: 807-815. [Crossref]

13. Greenwood B (2006) Editorial: 100 years of epidemic meningitis in West Africa - has anything changed? Trop Med Int Health 11: 773-780. [Crossref]

14. Survival and sequelae of meningococcal meningitis in Ghana [Internet]. [cited 2016 Jan 27]. Available from: http://ije.oxfordjournals.org/content/30/6/1440.full

15. Leimkugel J, Forgor AA, Gagneux S, Pflüger V, Flierl C, et al. (2005) An Outbreak of Serotype 1 Streptococcus pneumoniae Meningitis in Northern Ghana with Features That Are Characteristic of Neisseria meningitidis Meningitis Epidemics. $J$ Infect Dis 192: 192-199. [Crossref]

16. Harrison LH, Trotter CL, Ramsay ME (2009) Global epidemiology of meningococcal disease. Vaccine 27: B51-63. [Crossref]

17. Palmer SR (1989) Epidemiology In search of infectious diseases: methods in outbreak Investigation. J Epidemiol Community Health 43: 311-314. [Crossref]

18. Adriani KS, Brouwer MC, van de Beek D (2015) Risk factors for community-acquired bacterial meningitis in adults. Neth J Med 73: 53-60. [Crossref]

19. Mitchell AJ, Yau B, McQuillan JA, Ball HJ, Too LK, et al. (2012) Inflammasomedependent IFN-y drives pathogenesis in Streptococcus pneumoniae meningitis. J Immunol 189: 4970-4980. [Crossref]

20. Moore PS (1992) Meningococcal meningitis in sub-Saharan Africa: a model for the epidemicprocess. Clin Infect Dis 14: 515-525. [Crossref]

21. Lozano R, Naghavi M, Foreman K, Lim S, Shibuya K, et al. (2012) Global and regiona mortality from 235 causes of death for 20 age groups in 1990 and 2010: a systematic analysis for the Global Burden of Disease Study 2010. Lancet 380:2095-128. [Crossref] 
Mahamah BEE (2020) Investigation of meningitis outbreak after the introduction of Pneumococcal and MenA conjugate vaccines in two districts of Northern Region, Ghana from October 2015 to March 2016

22. Hentgen V, Levy C, Bingen E, Cohen R; groupe des pédiatres et microbiologistes de l'Observatoire national des méningites bactériennes de l'enfant (2008) [Group A streptococcal meningitis in children: clinical characteristics and outcome]. Arch Pediatr 15: S154-157. [Crossref]

23. Martins ER, Melo-Cristino J, Ramirez M; Portuguese Group for the Study of Streptococcal Infections (2012) Dominance of Serotype Ia among Group B Streptococc Causing Invasive Infections in Nonpregnant Adults in Portugal. J Clin Microbiol 50: 1219-1227. [Crossref]
24. Fish EN (2008) The X-files in immunity: sex-based differences predispose immune responses. Nat Rev Immunol 8:737-744. [Crossref]

25. Amur S, Parekh A, Mummaneni P (2012) Sex differences and genomics in autoimmune diseases. J Autoimmun 38: J254-65. [Crossref]

26. Weisfelt M1, van de Beek D, Spanjaard L, Reitsma JB, de Gans J (2006) Clinical features, complications, andoutcome in adults with pneumococcal meningitis: a prospective case series. Lancet Neurol 5: 123-129. [Crossref]

Copyright: (C2020 Mahamah BEE. This is an open-access article distributed under the terms of the Creative Commons Attribution License, which permits unrestricted use, distribution, and reproduction in any medium, provided the original author and source are credited. 